\title{
Notas sobre o déficit teórico da imaginação sociológica na filosofia da história de Kant
}

\author{
Daniel Tourinho Peres \\ danieltperes@uol.com.br \\ Universidade Federal da Bahia, Salvador, Bahia, Brasil
}

resumo 0 artigo procura argumentar contra a ideia de que a filosofia da história de Kant contaria com dois modelos de fundamentação: um modelo oficial, de natureza hipotéticoteleológica, e outro hermenêutico-explicativo, que, porém, acabaria por implodir o sistema. Trata-se de mostrar que há um único modelo, de natureza hermenêutica-explicativa, que não obstante faz uso de princípios hipotético-teleológicos. Mais ainda, que tal modelo está presente ao longo de diversos momentos do sistema, como na Doutrina do Direito, ou na Religião nos limites da simples razão.

palavras-chave Filosofia da História; Sistema; Esquema Imaginação; Razão; Kant

Para José A rthur Giannotti

Em um artigo onde procura rever alguns pontos da filosofia kantiana da história que ele julga em conflito, Axel H onneth opõe dois modelos de fundamentação da filosofia da história em Kant: aquele que chama de hemenêutico-explicativo, que se encontra, segundo suas palavras, "na parte não oficial" da sua filosofia; e o modelo de fundamentação teleológica, hipotético, que pensa o progresso como resultado de um propósito da natureza. $\mathrm{N}$ ão deixa de soar irônico $\mathrm{H}$ onneth dirigir a Kant, ao seu modelo de fundamentação teleológica, a mesma crítica que esse dirigiria a Herder1. Pois Kant sofreria de uma "desinibição especulativa [que] transparece nos escritos, sobretudo ali onde empreende (...) a tentativa de

R ecebido em 15 de junho de 2011. A ceito em 21 de julho de 2011. doispontos, Curitiba, São Carlos, vol. 8, n. 1, p.113-126, abril, 2011 


\section{4}

pôr a descoberto o plano secreto que deve ter atuado por trás dos atose das atrocidades históricas"; especulação na qual Kant emprega toda a força de sua imaginação, "apenas para nos sugerir que devemos reconhecer, mesmo nos dados mais adversos e lamentáveis de nossa história, o propósito secreto com que a natureza planejou nossa progressão moral" (H O N N ET H , 2008, p. 37.). H onneth opõe os dois modelos de fundamentação, justamente para ficar com aquele ponto de vista que pensa a história como produto de um processo de aprendizagem humano, modelo alternativo que consistiria, ao fim e ao cabo, "em uma tentativa de destranscendentalizar a razão prática, situando-a historicamente" (HONNETH 2008, p. 37.). O corre que tal modelo, segundo ele, "explode o sistema". N as páginas que seguem se procura apontar que tal modelo não apenas deixa o sistema intacto, mas é parte constitutiva dele.

$\mathrm{N}$ a quinta proposição de uma I deia de uma história universal de um ponto de vista cosmopolita, $K$ ant2 define nos seguintes termos o maior problema para humanidade: "O maior problema para o gênero humano, cuja solução a natureza o força, é o estabelecimento [E rreichung] de uma sociedade civil que administre universalmente 0 direito" (KAN T,VIII, p.22). 0 motor de que se serve a natureza é a insociável sociabilidade. Porém, focar a análise na insociável sociabilidade, mesmo que considerada como o fator do qual resulta uma luta social por reconhecimento (H O N N ET H , 2008, p. 38), é ver apenas um lado da questão: a luta por reconhecimento deve ainda poder ser traduzida em luta por liberdade. Sem dúvida a insociável sociabilidade é o dispositivo, no homem, que faz com que esse acabe por desenvolver todas as suas disposições morais. Tais disposições, porém, são apenas desenvolvidas ao longo da história, sem que tenham nela sua origem. Como afirma Kant, com a insociável sociabilidade ocorrem os primeiros verdadeiros passos (que levarão) da rudeza à cultura (...) e tem início, através de uma ilustração progressiva [fortgesetzte Aufklärung], a fundação de um modo de pensar que pode transformar, com o tempo, as toscas disposições naturais para o discernimento moral [sittlichen U nterscheidung] em princípios práticos 
determinados e assim finalmente transformar um acordo extorquido patologicamente para uma sociedade em um todo moral (KANT,VIII, p.21; KAN T, 1986, p.14)

U m dos princípios práticos determinados está justamente no estabelecimento de uma sociedade civil que administre universalmente 0 direito, como pretende a quinta proposição. E o início de um modo de pensar não se confunde com a origem de seu fundamento. Assim, o direito constitui justamente um daqueles núcleos a-históricos que constituem a filosofia kantiana da história33. E o que se pretende administrar é, em primeira instância, o direito à propriedade, na medida em que é aí, na determinação do meu e teu externos, que as diversas liberdades encontram seu ponto de atrito. D esse modo, a D outrina do $D$ ireito apresenta uma outra versão daquele que seria o mais difícil problema para a humanidade:

A indeterminação, tanto do ponto de vista da quantidade quanto da qualidade, do objeto externo que pode ser adquirido, faz desse problema (da aquisição originária particular) o mais difícil de ser resolvido. Ainda assim, tem de haver uma aquisição original qualquer do que é externo, pois nem toda aquisição pode ser derivada. Então, esse problema não pode ser abandonado como insolúvel e impossível em si. M as mesmo que seja resolvido pelo contrato originário, se tal contrato não se estender a todo o gênero humano, tal aquisição permanece apenas provisória. ${ }^{4}$ (KAN T,VI, 267; KAN T, 2005, p. 102).

U m pouco antes, Kant havia definido a entrada no estado civil como condição para o exercício mesmo da liberdade e do meu e teu externos (KAN T, VI, 256). Se no estado de natureza há efetivamente um meu e teu externos, é preciso reconhecer, porém, que seu estatuto é provisório ( $\mathrm{KAN} T, \mathrm{VI}, 256$ ). N a passagem entre estado de natureza e estado civil, 0 que está em questão não é o fundamento da propriedade, pois tal fundamento encontra-se no conceito de posse inteligível (possessio noumenon) ( $K A N T, V I$, p.245); o que está em questão é o esquematismo do conceito de direito, ou melhor, do meu e teu jurídico: "o modo de se ter algo como seu no estado de natureza é uma posse física, a qual tem a presunção de tornar-se jurídica por meio da unificação com a vontade de todos em uma legislação pública - comparativamente, enquanto se espera 


\section{6}

por tal estado, ela vale como jurídica" (KAN T, VI, p.257). O ra, a posse física vale como jurídica apenas na medida em que antecipa o estado jurídico. M elhor ainda, a afirmação de algo como meu, condição para a determinação de um meu e teu externos - que como tal, i.e., como externo, não pode ser originário, mas sempre adquirido, mesmo que originariamente - se revela como esquema do direito: "o direito como conceito da razão não pode ser tornado sensível a não ser por meio do esquematismo da posse, que pode ser empírica, e não do direito" (KAN T, X X III, p.277). $\mathrm{O} u$ ainda como Kant afirma em outro texto que prepara a $\mathrm{D}$ outrina do D ireito: "A diferença entre a posse física e a posse intelectual, ou virtual, é apenas a diferença entre 0 esquematismo dos conceitos jurídicos e os próprios conceitos jurídicos" (KAN T, XX III, p.273)5.

No limite, 0 ato de afirmar, de tomar algo como seu "apresenta" a ideia de contrato originário. C omo fenômeno, como ato no espaço e no tempo, trata- se de um ato unilateral, arbitrário. Em seu terceiro momento, porém, como apropriação [Z ueignung], tal ato é considerado, em ideia, como "ato de uma vontade universal e exteriormente legisladora" (KAN T,VI, p.258).Trata se justamente de fazer a passagem do sensível ao inteligível, da posse sensível à posse inteligível. M as aqui dois pontos: se as condições empíricas, i.e., sensíveis, devem ser deixadas de lado quando se trata de avaliar a determinação jurídica de algo como algo que pertence a alguém, e cujo uso, então, afetaria sua liberdade, por outro lado, sem a posse no fenômeno, as pretensões jurídicas sequer se fariam reconhecer. C omo escreve Kant: " 0 direito, como conceito da liberdade, não se dirige segundo a posse empírica, mas segundo a posse intelectual. Essa, porém, só pode tornar-se conhecimento por meio do esquematismo, caso contrário é vazia" (KAN T, XX III, p.277).

Distinguir entre 0 sensível e 0 inteligível, assim como entre 0 esquema e o conceito puro, é tarefa da reflexão transcendental. 0 ato de tomar posse de algo compõe-se tanto de elementos sensíveis como inteligíveis - e são esses últimos que tornam tal ato um ato de liberdade e juridicamente vinculante. A aquisição, e mesmo o direito à propriedade, esquematiza o direito, na medida em que este último é sempre uma relação entre sujeitos: trata-se sempre de uma relação entre pessoas (KAN T, VI, p.268). Assim, ao determinar algo como meu, determino, ao mesmo tempo, minha relação com todo outro sujeito racional. A 
passagem do estado de natureza para o estado civil é então o reconhecimento de que o postulado do direito público como lei permissiva provém da precariedade do direito privado: "você deve, numa relação de coexistência inevitável, sair, como todos os outros, do estado de natureza para entrar num estado jurídico, i. e. de justiça distributiva" (KAN T,VI, p.307). Assim a natureza, mesmo quando teleologicamente considerada, não instala o estado civil; apenas se toma um princípio que tem sua origem na razão prática como se fosse resultado do processo natural de socialização.

A quinta proposição de uma Ideia de uma história universal de um ponto de vista cosmopolita retira a ação humana do domínio próprio de uma teleologia natural para repô- la no domínio próprio da ação social, i . e., a sociabilidade não mais se determina como natural mas sim como civil, pois que o sujeito deixa de ser tomado como parte de um todo natural para ser determinado como parte de um todo moral, de uma comunidade moral de agentes livres e subordinados a uma vontade também comum e soberana. $\mathrm{N}$ a C rítica do Juíz o, Kant define a cultura como o fim último da natureza, e da cultura destaca as relações jurídicas como sua condição formal: "A condição formal, sob a qual somente a natureza pode al cançar esta sua intenção última [i. e., a cultura], é aquela constituição [V erfassung] na relação dos homens entre si, onde ao prejuízo mútuo da liberdade em conflito se opõe um poder conforme à lei num todo que se chama sociedade civil" (KAN T,V p.432, KAN T 1992, 362).

$M$ as qual é, afinal de contas, essa constituição? A constituição republicana, a única plenamente conforme com a ideia do contrato originário e cuja legislação está plenamente conforme ao direito natural, i. e., aquele direito a priori que pode ser reconhecido pela razão de cada homem [das a priori durch jedes M enschen Vernunft erkennbare R echt] (KAN T,VI, p.298). O ra, o direito natural, que integra o conjunto de leis a priori e necessárias, e que provêm do conceito do direito externo, constitui a forma do Estado em geral, o Estado em I deia [Staat im der Idee] (KAN T, VI, p.313). Formado pelos três poderes que constituem tantas relações da vontade unificada do povo e pela ideia pura de um soberano, é preciso que tal conceito puro, ou melhor, que tal ideia pura encontre seu modo de apresentação (KAN T, VI, 338). M onarquia, A ristocracia ou democracia são apenas, como formas empíricas de organização do poder e do Estado 


\section{8}

[Staatsform], a letra da legislação originária [ursprünglische $G$ esetz gebung] e possuem validade apenas subjetiva (KAN T,VI, p.340).

$M$ as 0 espírito daquele contrato originário (anima padi originarii)

contém a obrigação, para o poder constituinte [konstituierenden $\mathrm{G}$ ewalt], de tornar o modo de governo [R egierungsart] conforme àquela ideia [de contrato originário], e então, se isso não puder ocorrer de uma vez, que se vá mudando de modo paulatino e continuado até que, em seus efeitos, [o modo de governo] coincida com a única constituição que concorda com o direito, a constituição de uma república pura, de tal modo que as antigas formas empíricas (estatutárias), que apenas serviam para assegurar a submissão do povo, se resolvam na forma original (racional), a única que faz da liberdade princípio (KANT,VI, p.340).

K ant retoma essa questão no $\mathrm{C}$ onflito das F aculdades, então a partir da distinção entre república noúmeno e fenômeno, a última que apresenta a primeira, que é sua apresentação [D arstellung] (KAN T,VII, p.91)6. 0 ra, para pensarmos como resolver, com recursos da própria razão, o descompasso entre noúmeno e fenômeno, entre princípio inteligível e seu esquema, convém retomar, isso sim, al gumas passagens da R eligião nos limites da simples raz ão. No texto da R eligião nos limites da simples raz ão, diferentemente do que se passa na $D$ outrina do $D$ ireito, a teoria do esquematismo tem papel fundamental, ao menos em seu terceiro capítulo.

0 contrato originário é tão somente a ideia que determina a legitimidade, a conformidade ao direito, da passagem entre estado de natureza e estado civil, ou seja, ele apenas reflete 0 ato pelo qual o povo se constitui como Estado [D er A kt, wodurch sich das Volk selbst zu einem Staat kontituiert] (KANT,VI, p.315). D ecisivo é que a constituição se dê por meio de uma legislação externa, e isso em um duplo registro: pública, isto é, por todos reconhecível, e externa também quanto ao objeto, isto é, as ações externas que ela busca determinar. Assim, a ideia de contrato originário apresenta o fundamento de toda comunidade jurídica, comunidade de sujeitos livres e fundada sobre leis da liberdade. Fundada igualmente sobre 
leis da liberdade, só que internas, temos também a noção de uma comunidade ética. C omo afirma K ant, porém,

Sob mãos humanas, a ideia sublime - jamais plenamente alcançável [erreichbar] - de uma comunidade ética se apequena [sich verkleinert], a saber, [reduz-se] a uma instituição [A nstalt] - instituição que, no melhor dos casos, é capaz de representar-Ihe de modo puro apenas [quanto à sua] a forma; porém, o que quer que [nela instituição] diga respeito aos meios para alcançar [erreichen] tal todo [comunidade ética], sob as condições da sensibilidade humana é extremamente limitado. A final, como se pode esperar fazer algo de plenamente reto a partir de madeira tão torta? (KAN T,VI, p.100)

O ra, o final da citação remete, sem maior dificuldade, à quinta e à sexta proposições da I deia de uma história universal, com uma diferença: no texto de 1784 trata-se do estabelecimento [E rreichung] de uma sociedade civil que administre universalmente o direito, ou seja, de uma comunidade jurídica. O que é uma comunidade jurídica? É a associação na qual se vê determinado para cada um o teu e meu segundo leis públicas. 0 ra, 0 caráter público da lei, que ela repousa em uma vontade pública, é uma das notas que distinguem entre comunidade jurídica e comunidade ética, na medida em que a última, porque considera os deveres sempre como deveres de virtude, tem sua legislação como legislação interna, porque fundada na própria vontade do agente. A lei de virtude, diferentemente da lei jurídica, não pode ser externa, pelo menos quando considerada como fundamento de determinação do arbítrio. $M$ as se considerarmos mais de perto a questão, veremos que mesmo a legislação ética, legislação de virtude, a parte ser considerada como princípio de determinação da ação e portanto ser interna, pode se fazer externa, ou melhor, pública7. C omo é posśvel ler na R eligião:

[... ] uma associação de homens sob leis meramente [bloss] de virtude e por prescrição mesma de tal ideia [que faz da associação um dever], pode ser chamada de ética; e na medida em que tais leis são públicas, [pode ser chamada] (em contraste com a sociedade jurídico-civil) de sociedade ético-civil, ou de comunidade ética (KAN T,VI, p.94).

O ra, o contraste não está, então, no caráter público da lei, mas, isso sim, no tomar a associação mesma como um dever, ou seja, instituir tal associação é 


\section{0}

um dever e, diferentemente do que se passa com uma comunidade jurídica, ninguém pode ser coagido a entrar em tal associação. C omo Kant afirma logo a seguir: uma comunidade ética tem na virtude o seu princípio de unificação. Assim, ainda que seja um dever sair do estado de natureza ético e instaurar uma comunidade ética, cada um preserva o direito de permanecer num tal estado. De modo talvez o mais claro possível: “ U m estado ético-civil é aquele em que [os seres humanos] estão unificados sob leis, mas isso sem serem coagidos, isto é, apenas sob leis de virtude" (KAN T, VI, p.95). D e todo modo porque deveres de virtude dizem respeito a toda a espécie humana e o conceito de uma comunidade ética se refere, portanto, ao ideal de totalidade dos seres humanos. Porém,

[uma] multiplicidade de seres humanos unificados sob esse propósito ainda não pode, como tal, ser chamada de comunidade ética, mas apenas de sociedade [ $G$ esellschaft] particular que luta pelo consenso de todos os seres humanos (em verdade de todos os seres racionais finitos) de modo a estabelecer [erreichen] um todo ético absoluto, do qual cada sociedade particular é apenas uma representação ou esquema (KAN T, IV, p.96).

C ada sociedade particular é apenas a representação ou esquema daquela ideia sublime. Ainda no texto da R eligião, quando trata de determinar tal comunidade em termos de sua institucionalização, K ant tece uma outra distinção, agora entre igreja invisível e igreja visível: a primeira, que mais uma vez é uma mera ideia, a segunda, a igreja visível, que é a união real, mas em conformidade com o ideal. De modo ainda mais claro: "A verdadeira igreja (visível) apresenta [darstellt] o reino moral de Deus na Terra, até o ponto em que tal reino pode ser realizado entre homens" (KAN T,VI, p.106).

$\mathrm{M}$ as como $\mathrm{K}$ ant reconhece, a "constituição de toda igreja provém de alguma fé histórica [historichen G lauben]" (KAN T,VI, p.102). N a verdade, a fé histórica faz a passagem, com recursos da razão prática, entre 0 inteligível e o sensível, entre a igreja invisível - imagem originária (arquétipo) que se encontra no fundamento de qualquer imagem derivada (ectipo) - e a igreja visível. D ito de um outro modo, "o supra-sensível se põe como matriz dum espelhamento"( GIAN N OTTI, 1986.), no qual o sensível, ou o histórico, funciona como tipo. A revelação [0 ffen- 
barung], interpretada como fé histórica, se pretende ter o testemunho de fatos, reconhece sua precariedade sensível: "sua influência se estende apenas até onde se estende, no tempo e no espaço, a força retórica daquilo que ela comunica [die $\mathrm{N}$ achrichten in B eziehung aus das Vermögen ihre G laubwürdigkeit]" (KAN T,VI, p.103). M ais ainda, a fé histórica só se afirma como racional na medida em que se põe como veículo daquela única fé cuja razão de convencimento se faz a todos comunicar: a simples fé na razão [blosser Vernunftglaube] ou fé pura religiosa. Aqui, no texto da R eligião, Kant retoma questão que discute desde 1786, em 0 que significa orientar-se no pensamento, no contexto da "polêmica sobre o panteísmo". E lá, como aqui, se trata sempre de fazer a passagem entre inteligível e sensível com recursos da própria razão: como ele então afirmava, sua intenção está em mostrar que somente a razão pode orientar a si mesma, e não um "misterioso sentido de verdade [W ahrheitsinn], nenhuma intuição transcendente [überschwengliche] com o nome de fé, na qual poderiam ser introduzidas, sem o acordo da razão, revelação e tradição" (KANT, VIII, p.134).Tradição e revelação não podem provir da razão como razão pura, mas encontram na razão o seu cânon, isto é, naquela fé que se orienta pela razão e que não possui qualquer estatuto (KAN T,VII, p.36). Assim, são formas do modo sensível de representar (KANT,VII, p.36), mas que, em última instância, tratam sempre de representar a lei moral. Enquanto formas sensíveis, porém, revelação e tradição encontram-se na base daquela"legislação estatutária que só pode ser tomada como contingente, como algo que não pôde - e nem pode - alcançar todos os homens, de forma que, então, não pode ser tomada como a todos obrigante" (KAN T,VI, p.104).

Para encaminhar uma conclusão, no caso do direito, da legislação jurídica, ainda que se deva também considerar, do ponto de vista da razão pura, o direito positivo como contingente ${ }^{8}$, é preciso reconhecer, porém, que ele se apresenta como instância normativa. Para usar a expressão de Waldron, temos, no âmbito das relações sociais que recaem sob uma legislação externa, um positivismo normativo, cuja virtude está na univo- 


\section{2}

cidade da lei e da legislação, e não porque, em seu conteúdo, lei e legislação refletem o ponto de vista de todos (WALD R O N, 1996, p. 1535). A univocidade da lei, porém, não apaga a pluralidade da razão, quando nada porque a necessidade da lei não elimina a contingência de sua positividade, ou seja, o elemento histórico, empírico e portanto contingente de toda legislação positiva. Pois se a legislação positiva, em suas articulações, se mostra compatível e congruente com a razão, não o faz excluindo outras articulações possíveis 9 . Trata- se assim de garantir aquela perspectiva para a faculdade de julgar, que K ant formula no $\S 40$ da terceira C rítica, segundo a qual comparamos nosso juízo não tanto com o atual juízo do outro, mas com o seu juízo possível. O ra, a R evolução Francesa mostra a realidade de uma outra articulação jurídica possível, e assim apresenta, de modo mais congruente com o interesse refletido de todos, a ideia de direito. O u seja, o interesse que os desdobramentos da R evolução Francesa desperta em todos, isto é, no público espectador, lança luz sobre o descompasso entre fato e norma, e amplia, com isso, o reconhecimento de determinações da razão. A passagem entre um plano e outro só pode ser realizada discursivamente (KAN T,VI, p.135), ainda que com 0 auxílio da imaginação10 - de uma imaginação, porém, que encontra na razão sua medida, e isso mesmo que a razão seja compreendida como modo de pensar alargado, como uso público - e comum - da razão. De todo modo, é a razão que realiza a passagem. Como Kant escreve no texto da R eligião:

$\mathrm{N}$ ão há, assim, qualquer norma para a fé eclesial exceto a Escritura [Schrift]; e nenhum outro expositor a não ser a religião da razão e a erudição quanto à escritura [S chriftgelehrsamkeit] (a qual lida com 0 elemento histórico da Escritura). D essas duas, apenas a primeira é autêntica e válida para todo o mundo, enquanto a segunda é meramente doutrinal - seu objetivo é a transformação da fé eclesial - de um dado povo e em um dado tempo - em um sistema determinado, permanente e que se sustente (KAN T,VI, p.114).

O ra, a norma para o direito positivo está na constituição também positiva - a política da razão está para o direito assim como a religião da razão está para a fé eclesial. A filosofia da história nos fornece uma visão moral do mundo à qual podemos dar nosso assentimento, de modo que o plano 
secreto da natureza tem como contrapartida sua comunicação universal. A ssim, não há, como afirma $\mathrm{H}$ onneth, uma filosofia da história oficial e outra não oficial (HO N N ETH , 2008, p.42), mas apenas dois pontos de vista convergentes, determinação e reflexão, que circunscrevem a unidade da razão. N ão é a filosofia da história, como acredita Terry Pinkard (PIN K AR D. 2009, p.227), que exige a mediação; antes, é a necessidade de mediação que exige uma filosofia da história como seu meio de realização. Se temos uma confiança reflexionante [reflectirende G laube] (KAN T, VI, p.52) no progresso histórico rumo ao melhor, tal como representado pela imaginação; se temos essa confiança que nos torna compreensível a possibilidade mesma da realização da ideia do direito, é porque temos uma certeza determinante de estarmos submetidos ao imperativo da razão prática. Assim, é a razão que orienta o trabalho da imaginação, e não o contrário. 0 que não se pode é misturar os registros e tomar alhos por bugalhos.

1 U ma boa análise da relação $\mathrm{K}$ ant e $\mathrm{H}$ erder, onde se encontram acentuados os pontos de acordo, pode ser encontrada em WO O D, A. 2008.

2 K ant é citado sempre na edição daA kademia, volume e número da página. Foram utilizadas ainda as seguintes traduções: I déia de uma história universal de um ponto de vista cosmopolita, trad. R icardo R Terra e R odrigo N aves, São Paulo, Brasiliense, 1986. Para a “D outrina do Direito": A M etafísica dos C ostumes, trad. José Lamego, Lisboa, Gulbenkian, 2005, bem como C rítica da F aculdade de Julgar, trad. Antônio M arques eValério R ohden, Lisboa, IN C M , 1992.

3 Com relação ao princípio moral, mas que vale igualmente para o direito, Pauline K leingeld escreve o seguinte: “A filosofia da história de K ant possui um núcleo 'ahistórico'. Este repousa no seguinte: 0 valor absoluto do princípio moral mesmo é posto acima de qualquer surgimento histórico [geschichtliche Entstehung]. 0 princípio moral não surge em um determinado momento do tempo [Zeitpunkt], apenas torna-se cada vez mais claro. Sempre foi e será objetivamente válido, apenas será, lenta e progressivamente, subjetivamente reconhecido como tal" Cf. K LEIN GELD, P., 1995, p. 207. 0 mesmo ponto é tratado em K LEIN GELD, P., 1999.

4 U ma interpretação interessante da filosofia política de Kant centrada na noção de direito provisório pode ser encontrada em ELLIS, E., 2005.

5 Sobre a relação entre posse física e posse inteligível, bem como a passagem do estado de natureza (de direito privado) para o estado civil (de direito público), ver PER ES, D.T., 2004, em especial capítulos 2 e 3. 


\section{4}

$6 \mathrm{O}$ ra, se $\mathrm{O} C$ onflito das $\mathrm{F}$ aculdades apresenta aquele modelo de racionalidade hermenêuticoexplicativo que fundamenta a noção de progresso como aprendizado moral socialmente compartilhado e historicamente situado, e se essa forma de racionalidade está presente também na $D$ outrina do $D$ ireito, não se vê muito bem porque teríamos, como pretende $\mathrm{H}$ onneth, qualquer explosão do sistema. U ma interpretação ampla da filosofia kantiana que avalia a sua contribuição para uma concepção hermenêutica da racionalidade é realizada por M AKKR EEL, R . A., 1990. Essa figura da razão será ainda mais presente $R$ eligião nos limites da simples razão.

${ }^{7}$ Conforme observei em outro lugar: "N a R eligião, e é isso que nem a $F$ undamentação nem a $C$ rítica da $R$ az ão P rática deixavam entrever, a legislação moral, interna, de algum modo deve se instituicionalizar, isto é, se tornar pública sem perder, porém, seu caráter interno" (PER ES, D. T., 2009).

${ }^{8}$ Cf., p. ex, KLEIN GELD, P., 2008, p. 526.

9 O nora $\mathrm{O}$ 'N eill escreve a propósito da religião: "a religião da razão, do ponto de vista de $K$ ant, nos mostra que muitas articulações religio sas e históricas so bre a esperança são possíveis, que algumas articulações são congruentes e compatíveis entre si, mas não nos mostra que um tipo de esperança é requerido à exclusão de todos os demais' (O 'N EILL, O, 1997, p. 308).

10 Ver PER ES, D. T., 2009. Pauline Kleingeld, em "Kant on historiography and the use of regulative ideas", afirma o seguinte: "Sua sugestão na I dêa de uma história universal certamente necessita ser suplementada por uma teoria da argumentação histórica, que estabeleceria critérios para avaliar o mérito relativo de um modelo frente a outros candidatos, teoria que explorasse um pouco mais noções como coerência narrativa e compreensão explanativa" (KLEIN GELD, P.2008, p. 527).

\section{Referências bibliográficas}

ELLIS, E. 2005. K ant's Politics: provisional theory for an uncertain world. $\mathrm{N}$ ew $\mathrm{H}$ aven:Yale U niversity Press.

GIAN N OTTI, J.A. 1986. "Kant e o espaço da história universal." In: TER R A, R . (org). Immanuel K ant: I deia de uma história universal de um ponto de vista cosmopolita. São Paulo: B rasiliense.

H O N N ETH , A. 2008. "A irretrocedibilidade do progresso." In: PER ES, D.T. et alli (org). Tensões e Passagens: filosofia crítica e modernidade. U ma homenagem a RicardoTerra. São Paulo: Esfera Pública.

KAN T, I. G esammelte Schriften. s/ d; Berlin:Walter de G ruyter. 
. 1986. Ideia de uma história universal de um ponto de vista cosmopolita, TER R A, R . R e N AVES, R. (trad.). São Paulo: B rasiliense. . C rítica da F aculdade de Julgar. 1992. M arques, A e R ohden,V (trad.). Lisboa: I N C M ,.

. 2005. "D outrina do Direito". In: A M etafísica dos C ostumes. Lamego, J. (trad.). Lisboa: Gulbenkian.

KLEIN GELD, P. 1995. F ortschritt und V ernunft: Z ur G eschichtsphilosophie. W ürzburg: Königshausen \& N eumann.

, 1999. "K ant, $\mathrm{H}$ istory and the idea of moral development." In: $\mathrm{H}$ istory of P hilosophy Q uarterly. C hicago, vol. 16, no.1, pp. 59-80, Disponibilidade: [acesso]. [janeiro].

. 2008. "K ant on historiography and the use of regulative ideas." In: Studies in H istory and Philosophy of Science, vol.39, no.4, pp. 523-528. Disponibilidade: Elsevier ScienceD irect Complete. [dezembro] M AKKR EEL, R . A. 1990. Imagination and Interpretation in K ant: the hermeneutical import of the $C$ ritique of Judgment. $C$ hicago: $C$ hicago U niversity Press.

O 'N EILL, O. 1997. "Kant on R eason and R eligion". In:

PATTER SO N , G.B. (org.), T heTanner L ectures on H uman ValuesV. 18. Salt Lake City: U niversity of U tah Press.

PER ES, D.T. 2004. K ant: M etafísica e P olítica. Salvador-São Paulo: EDU FBA/ U N ESP.

. 2009. "N otas sobre D ireito, Política e R eligião em Kant." In: ST O R CK, A. C . e LISBO A, W. B, N orma M oralidade e interpretação: temas de filosofia política e do direito. Porto Alegre: Linus.

. 2009. “A filosofia da história entre a retórica e 0 conhecimento objetivo." In: M ART IN S, C.A. e M AR Q U ES, U.R. de A. K ant e o kantismo: heranças interpretativas. São Paulo: Brasiliense. 


\section{6}

PIN KAR D, T. 2009. "N orms, facts, and the philosophy of history." In: RORTY, A. O. e SC H M IDT, J. (orgs.) K ant's I dea for a U niversal H istory with a C osmopolitan A im. Cambridge: C ambridge U niversity Press.

WALDRON, J. 1996. “Kant's Legal Positivism." H arvard L aw R eview, [local da publicação] Vol. 109, N 0. 7, [intervalo de págs do artigo] pp. 1535- 1566.

WO OD,A. 2008. "H erder and Kant on H istory:T heir Enlightenment Faith." In: JO R GEN SEN, L. and N EW LAN DS, S. (orgs.) M etaphysics and the $\mathrm{G}$ ood: T hemes from the P hilosophy of R obert M errihew A dams. O xford: O xford U niversity Press. 